\title{
HIGH-STABILITY FOAM OF SILICA NANOFLUID TO OVERCOME LIQUID LOADING IN ENHANCING NATURAL GAS PRODUCTION
}

\author{
Hendrix Abdul Ajiz | Lizda Johar Mawarani | Widiyastuti | Heru Setyawan*
}

\footnotetext{
${ }^{1}$ Dept. of Chemical Engineering, Institut Teknologi Sepuluh Nopember, Surabaya, Indonesia
}

\section{Correspondence}

*Heru Setyawan, Dept of Chemical Engineering, Institut Teknologi Sepuluh Nopember, Surabaya, Indonesia. Email: sheru@chem-eng.its.ac.id

\section{Present Address}

Gedung Teknik Kimia, Jl. Teknik Kimia, Kampus ITS Sukolilo, Surabaya 60111, Indonesia

\begin{abstract}
One of the promising solutions to overcome the liquid loading problem in natural gas production is using a foaming agent. The extreme condition in the gas well causes the foam used tends to break up. Therefore, it is required to enhance the foam stability by adding a stabilizer agent. This research aims to investigate the effect of silica nanoparticles as a surfactant stabilizer to obtain a high-stability foam using silica nanofluid. Silica nanofluid was synthesized from sodium silicate solution by the solgel method. Then, the colloidal silica was added to the surfactant solution without a coupling agent. The effects of aging time and silica concentration were investigated. The results show that the surface tension tends to increase with the increase of aging time and silica concentration but decrease in foam stability which is indicated by a decrease in the foam half-life time. The best foam stability is obtained in silica nanofluids with an aging time of 6 hours and a silica concentration of $30 \mathrm{ppm}$, which shows a foam half-life of 42 hours and can improve foam stability with several parameters representing the conditions of the gas well.
\end{abstract}

\section{KEYWORDS:}

Adsorption, Foam Stability, Foaming Agent, Silica Nanofluid, Surface Tension

\section{1 | INTRODUCTION}

Nanotechnology has been developed rapidly and applied in various fields. One of them is nanofluid, which has wide application supported to increase natural gas production to overcome the liquid loading problem ${ }^{[1] 2]}$. Usually, the foaming agent used to overcome liquid loading is surfactants, with their advantages consisting of process efficiency and low costs relatively. Surfactants can reduce the density and surface tension of the liquid inward, thereby reducing the gas velocity needed to lift droplets to the liquid surface. Stable foam as a foaming agent in gas conditions is needed to overcome liquid loading $[3]$. 
Foam stability covers three main things. Those are drainage, coarsening, and coalescence, which is the aging process in foam. Drainage separates the liquid and gas phases in the foam film layer that occurs due to gravity; the dry foam film layer becomes less elastic and unstable so that the foam becomes more easily ruptured. The drainage event is followed by coalescence and coarsening, which combine foam into a larger size due to gas diffusion events through the film layer on the foam. The foam becoming larger has low stability, causes the foam to become unstable and break in a short time ${ }^{3}$.

Efforts to improve the foam stability of surfactants have been carried out by improving the chemical structure of surfactant and added silica nanoparticles synthesized from Tetra Ethyl Ortho Silicate (TEOS) using the Stober method ${ }^{\sqrt{4}}$. Silica is a material that can be applied as a stabilizer for certain fields such as a support for another material due to the morphology of the particles can be controlled ${ }^{[7 \mid 9]}$. They got results that showed an increase in foam stability by adding silica nanoparticles. The utilization of TEOS as a source of silica has eased in controlling its particle size but is expensive and has a more complicated synthesis process than silica nanoparticles synthesized from sodium silicate $\left(\mathrm{Na}_{2} \mathrm{SiO}_{3}\right)^{[10+12}$. In a previous study, $\mathrm{Na}_{2} \mathrm{SiO}_{3}$ succeed in improving foam stability by increasing its half-life. This proves that nanoparticles synthesized from sodium silicate can be used as surfactant stabilizers 13 [14].

This work aims to study the effect of colloidal silica adding to anionic surfactant sodium lauryl sulfate (SLS) on foam stability. The colloidal silica was synthesized from sodium silicate solution. The synthesis in a stable colloidal phase does not require special treatment, and the silica from sodium silicate could form bonds with surfactants without a coupling agent because it already has a silanol group $(\mathrm{Si}-\mathrm{OH})$ that can form physical bonds with hydrophilic groups on surfactants 3.13$] 15,16$. The SLS and the SLS-silica nanofluid were tested for their performance as a foaming agent in water both in the absence and in the presence of salinity. The effect of temperature on foam stability is also investigated.

\section{2 | PREVIOUS RESEARCHES}

Research on silica nanoparticles as a stabilizer of surfactants has been carried out in several stages of development. The selection of silica sources as materials in the synthesis of nanoparticles is also diverse. In several studies, the selected silica source is Tetra Ethyl Ortho Silicate (TEOS). The selection of TEOS as a source of silica is based on the speed of the hydrolysis and condensation reaction, which is relatively slow so that it is easy to control. In addition to silica sources, the methods used in the process of dispersing nanoparticles in fluids also vary. Silica nanoparticles can be dispersed using ultrasonic waves with a dispersion time of up to 12 hours. To produce a strong bond between surfactant and silica, a coupling agent is also added to make it more stable. The research that has been developed shows that the concentration in nanofluid research is divided into three main things, namely the source of silica, the dispersion method, and the auxiliary material to produce a stable colloidal dispersion. In this study, sodium silicate was chosen as the source of silica. Besides having economic value, sodium silicate also has a hydroxyl group that TEOS does not have, which must pass through the reaction stage in alcohol conditions. Because sodium silicate already has a hydroxyl group, it will facilitate the surfactant immobilization process on the silica surface without adding a coupling agent. The resulting nanofluid has a high zeta potential value so that the stability of the silica particles in the colloidal phase can be maintained for a long time.

\section{3 | MATERIAL AND METHOD}

\section{1 | Material}

The materials used in this study are sodium lauryl sulfate (SLS) (CV. Citra Sari Kimia), sodium silicate with $\mathrm{SiO}_{2}$ content of $28 \%, \mathrm{SiO}_{2}: \mathrm{Na}_{2} \mathrm{O}=3.3$ (PT. PQ Silicas Indonesia), demineralization water (PT. Brataco), potassium hydroxide (KOH) p.a. Merck, hydrochloric acid (HCl) 37\% (Mallinckrodt), floral-007 resin, $\mathrm{NaCl}$, n-Hexane p.a.

\section{2 | Nanofluid preparation}

Synthesis of colloidal silica follows the procedure used previously ${ }^{[17]}$. Briefly, the diluted sodium silicate solution was mixed with the $\mathrm{H}^{+}$ion resin to exchange the $\mathrm{Na}^{+}$ions for obtaining active silicic acid of $\mathrm{pH}$ 2. Then, some $0.1 \mathrm{M} \mathrm{KOH}$ solution was added dropwise into the silicic acid until the $\mathrm{pH}$ became 8 to induce silica precipitation. The colloidal silica with a concentration of 0 to $50 \mathrm{ppm}$ was then added to the SLS surfactant solution. The SLS concentration was varied from 0.5 to 5 of the critical 


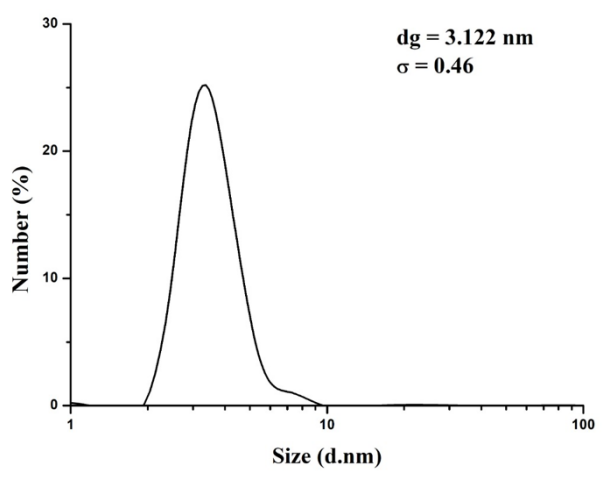

FIGURE 1 The particle size distribution of silica nanofluid.

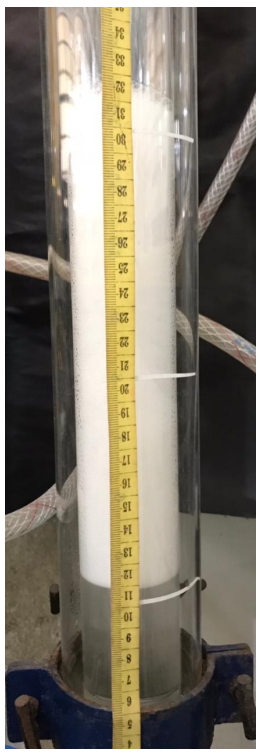

(a)

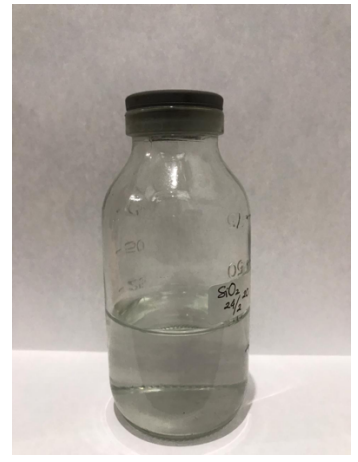

(a)

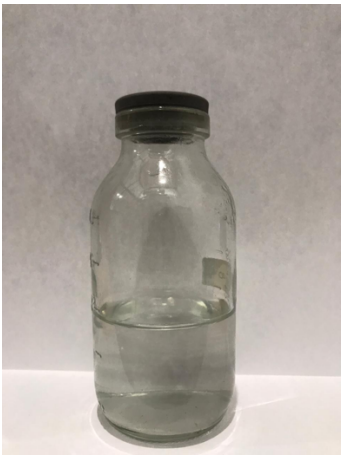

(b)
FIGURE 2 Photograph colloidal silica after being stored for (a) 15 days and (b) 120 days.

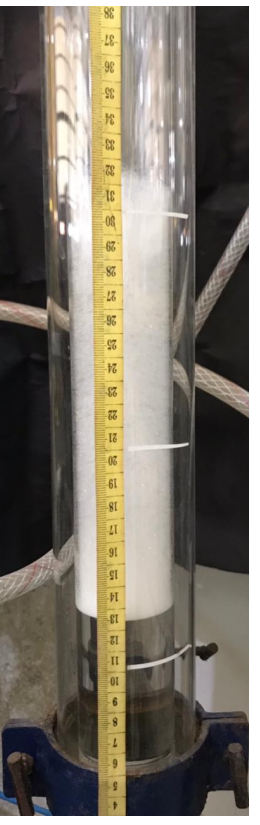

(b)

FIGURE 3 Changes in foam height 5 CMC SLS solution at (a) initial and (b) after 5 minutes at ambient.

micelle concentration (CMC). The CMC value of SLS in water, as determined based on the surface tension measurement, was found to be $600 \mathrm{mg} / \mathrm{L}$. The mixture was then aged to allow the adsorption of the SLS onto the silica surface with aging time varied from 0 to $24 \mathrm{~h}$. When studying the effect of salinity, $\mathrm{NaCl}$ with a concentration varied from 15,000 to 18,000 ppm was added into water. For the case of investigating the effect of hydrocarbon, n-hexane with a concentration varied from 10 to 50 (

\section{3 | Characterization}

The colloidal silica's zeta potential and particle size distribution were measured using a Zetasizer instrument (Malvern Model Nano ZS). The foam stability was evaluated using Ross Miles apparatus according to ASTM D-1173. Briefly, $200 \mathrm{~mL}$ of surfactant solution was dropped from a separating funnel with a distance of $90 \mathrm{~cm}$ away from the surface of $50 \mathrm{~mL}$ water put in the bottom of a glass column of $5 \mathrm{~cm}$ in diameter. Then, the foam height was recorded periodically for $30 \mathrm{~min}$. In addition, the half-life time of the foam was determined in a $1000 \mathrm{~mL}$ graduated cylinder. The foam was generated by directly mixing the surfactant, either free or immobilized on silica, with water-the surface tension measured by a capillary method. 


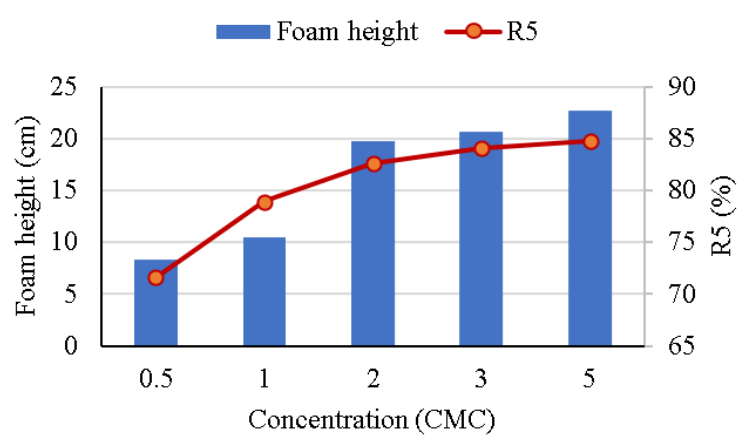

FIGURE 4 Foamability and foam stability of SLS solution.

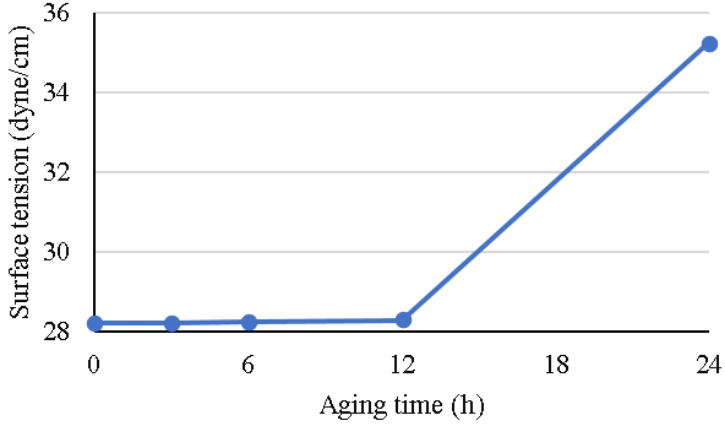

FIGURE 5 The effect of aging time on surface tension. The SLS and silica concentrations are respectively $5 \mathrm{CMC}$ and $30 \mathrm{ppm}$.

\section{4 | RESULTS AND DISCUSSION}

The particle size distribution of silica particles in the colloidal silica is shown in Figure 1 The size distribution is relatively narrow, with a geometric mean size of approximately $3.12 \mathrm{~nm}$ and a standard deviation of $0.46 \mathrm{~nm}$. The colloid with the silica nanoparticles of size $3.12 \mathrm{~nm}$ meets the criteria for use as a stabilizer to immobilize surfactant to form a stable nanofluid. In addition, the colloidal silica had a zeta potential of approximately $-34.2 \mathrm{mV}$. The absolute value of zeta potential is greater than the lower threshold of zeta potential, which is $30 \mathrm{mV}$, for the colloid to be considered stable. The colloidal silica was put in a glass bottle and stored in a safe place for 120 days to confirm its stability.

Figure 2 shows the photographs of the colloidal silica after 15 and 120 days. It can be observed that the colloid remained clear, nearly the same as the initial condition, and no residues appeared. This confirmed the result of zeta potential measurement that the colloidal silica is relatively stable.

When the nanofluid was dropped to water in the Ross Miles apparatus, the foam was formed immediately and then gradually collapse. Figure 3 shows the typical time evolution of foam height in the Ross Miles apparatus. From the figure, the foam stability was determined as the percentage of foam height after five minutes compared to the initial foam height, which hereafter will be referred to as R5. Figure 4 shows the effect of SLS concentration on the R5 values. The greater the SLS concentration was, the higher the R5 was. It indicates that the foam stability was enhanced with the increase of SLS concentration. The highest stability of foam was shown at an SLS concentration of 5 CMC, which corresponds to the height reduction of foam of approximately $15.2 \%$ after $5 \mathrm{~min}$. Thus, the following discussions on the effect of foam stabilization using silica nanoparticles will be based on the experiments using the SLS concentrations of 5 CMC.

SLS surfactant as the foaming agent was attached to the silica surface by contacting the SLS with silica nanoparticles in the colloid to stabilize the foam generated. The mixture of SLS and silica nanofluid was aged for a certain time to ensure the complete attachment of SLS onto the silica surface. Figure 5 shows the effect of aging time on the surface tension of nanofluid at silica concentration of $30 \mathrm{ppm}$, a typical value used previously in the published literature. The surface tension tended to increase with silica concentration, from approximately 28.2 to $35.2 \mathrm{dyne} / \mathrm{cm}$. It appears that it needs some time for the SLS to attach to the silica surface completely.

Figure 6 shows the effect of silica concentration on the surface tension and the half-life time of the foam generated. The aging time was six h. The surface tension increased from approximately 28.17 dyne $/ \mathrm{cm}$ at zero silica concentration to 28.30 dyne $/ \mathrm{cm}$ at a silica concentration of $50 \mathrm{ppm}$. As expected, the increase in surface tension would increase the foam stability, as shown by the increase of half-life time from $17 \mathrm{~h}$ (without silica) to $41 \mathrm{~h}$ with a silica concentration of $50 \mathrm{ppm}$. These results suggest that SLS can be attached well onto the silica surface. The hydrophilic nature of the silica surface drives the head groups of the SLS, which also possess hydrophilic properties and the same polarity, to attach to the silica surface.

In addition to increasing the surface tension, the surfactant attaches to the silica surface also enhances the stability of the colloidal silica. As discussed before, the zeta potential of colloidal silica without the presence of SLS takes the value of approximately 


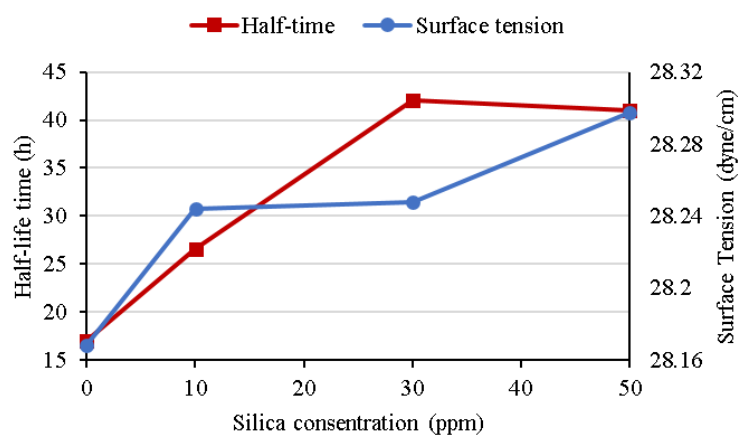

FIGURE 6 The effect of silica concentration on the surface tension and half-life time of the foam. The SLS concentration is $5 \mathrm{CMC}$, and the aging time is six $\mathrm{h}$.

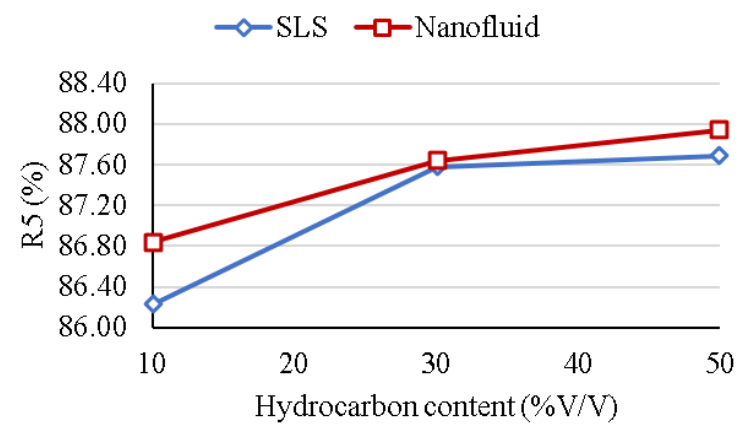

FIGURE 8 The effect of $n$-Hexane content on foam stability. The nanofluid was prepared using 5 CMC SLS and $30 \mathrm{ppm}$ silica aged for six $\mathrm{h}$.

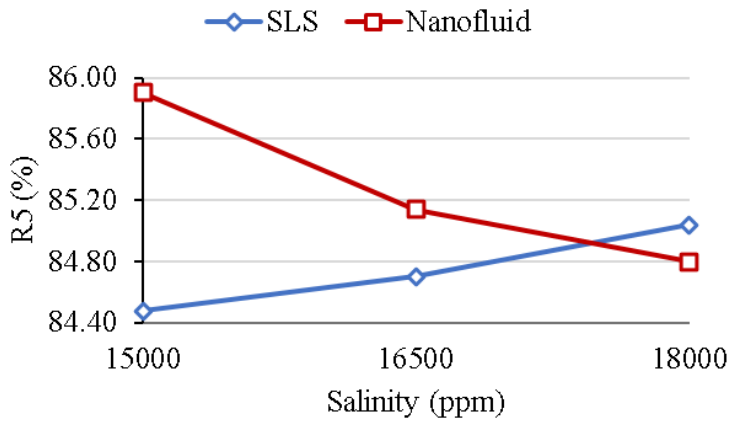

FIGURE 7 The effect of $\mathrm{NaCl}$ content on foam stability. Nanofluid was prepared using a mixture of 5 CMC of SLS and $30 \mathrm{ppm}$ silica with an aging time of $6 \mathrm{~h}$.

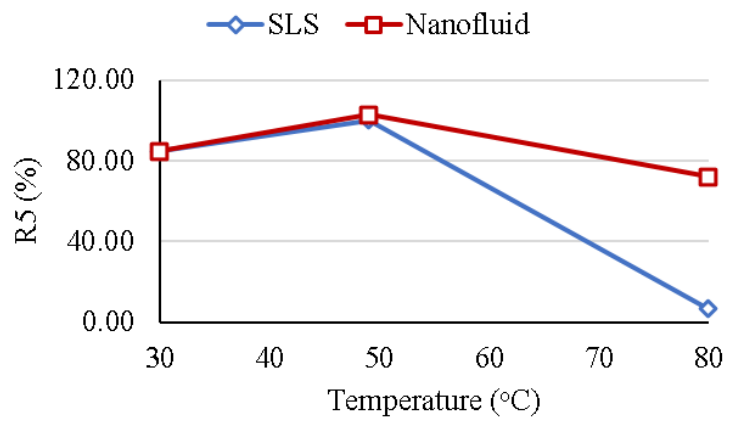

FIGURE 9 The effect of temperature on foam nanofluid was prepared using 5 CMC SLS and $30 \mathrm{ppm}$ silica aged for six $h$.

$-34.2 \mathrm{mV}$. The absolute value of zeta potential increased significantly to $-52.8 \mathrm{mV}$ with SLS attached to the silica surface. The high value of zeta potential indicates that the colloid is more stable. In addition, it appears that SLS also has the function of stabilizing the colloidal silica through steric stabilization. As the head groups of the SLS are strongly anchored to the silica surface, their tails are probably freely swung. The free-swing tails may provide the protective layer extends into the solution that can impose a barrier, in addition to the electrostatic barrier, to close particle approach ${ }^{[3][1]-20]}$. This double action improves more the stability of the silica colloid. Thus, SLS immobilized on silica surface seems to have two functions: enhance the colloid stability and improve foam stability.

In the real field, water in the gas well typically contains salinity and hydrocarbons that may influence the effectivity of nanofluid to form foam. Figure 7 shows the effect of salinity, represented by $\mathrm{NaCl}$, on the foam stability. Without silica, i.e., only SLS, the foam stability tended to increase with an increase in salinity, as shown by an increase in the R5 value from $84.5 \%$ with no salinity to $85.0 \%$ at a salinity of $18,000 \mathrm{ppm}$. On the other hand, the foam stability tended to decrease in the case of nanofluid. The R5 value decreased from $85.5 \%$ at zero salinity to $84.8 \%$ at $18,000 \mathrm{ppm}$. It may be caused by the electrical pressure generated on the foam film due to the suppression of the electrical double layer at the gas/liquid interface by salt ions. The electrical pressure generates a double pressure on the foam film that causes the foam to rupture more easily.

The effect of hydrocarbon content, represented by n-hexane, on the stability of foam generated with the assistance of nanofluid and surfactant alone is shown in Figure 8 For both cases, the stability of foam tended to increase with the increase of hydrocarbon content, as indicated by the R5 value. The R5 value for surfactant alone increased from $86.2 \%$ at hydrocarbon content of $10 \%(\mathrm{~V} / \mathrm{V})$ to $87.7 \%$ at hydrocarbon content of $50 \%(\mathrm{~V} / \mathrm{V})$. It increased from $86.8 \%$ at $10 \%(\mathrm{~V} / \mathrm{V})$ to $87.9 \%$ at $50 \%(\mathrm{~V} / \mathrm{V})$ for the case of nanofluid. It appears that the SLS-silica nanofluid had better performance in terms of foam stability than the surfactant 
alone. Thus, although hydrocarbons are typically hydrophobic and tend to behave as antifoam, SLS-based foaming agent, either free or immobilized, seems to be suitable as a foaming agent for use in the gas well that contains a portion of hydrocarbons. The effect of temperature on the stability of foam, represented by the R5 value generated by surfactant and nanofluid, is shown in Figure 9 For both cases, the foam stability initially increased, reached a maximum value, and decreased again. However, the R5 value for SLS-silica nanofluid is greater than that of SLS alone. At high temperatures, i.e., $80^{\circ} \mathrm{C}$, the performance of SLS-silica nanofluid is much more profound. The $\mathrm{R} 5$ value of nanofluid at $80^{\circ} \mathrm{C}$ is slightly lower than that of room temperature, which takes approximately $72 \%$. It means that the foam height is slightly reduced by only $28 \%$.

On the other hand, for foam generated by SLS, the R5 value is only $6.85 \%$, meaning that the foam nearly already collapses. The stability of foam generated by SLS-silica nanofluid at high temperatures is likely due to the presence of silica that can resist high temperatures. The dense layer of foam shell formed by silica nanoparticles makes the foam can withstand the pressure exerts by gas in the bubbles.

\section{5 | CONCLUSION}

The addition of nanoparticles as the stabilizer can increase the stability of the surfactant. Silica nanoparticles can be applied as a stabilizer of SLS in a colloidal phase. The addition of silica synthesized from sodium silicate to the SLS solution to produce SLSsilica nanofluid has been successfully improved the foam stability significantly, even in a simulated environment similar to the gas well. The surface tension and the foam stability increase significantly by increasing the aging time and silica concentration. The presence of silica as the place to immobilize SLS surfactant significantly improves foam stability. In this case, silica serves as a stabilizer in improving foam stability. This nanofluid system appears to be promising as the foaming agent used in gas wells or other environments containing high salinity and temperature. In the future, it is hoped that the development of nanofluid technology can be applied by utilizing abundant materials such as sodium silicate as a silica source to overcome liquid loadings in gas wells.

\section{ACKNOWLEDGEMENT}

This work is part of research funded by the Ministry of Technology Research and Higher Education through the Doctoral Dissertation Research Program in 2019-2020.

\section{CREDIT}

Hendrix Abdul Ajiz: Conceptualization, Methodology, Writing - original draft preparation, and Supervision, Formal analysis and investigation, Writing - review and editing, Resources. Lizda Johar Mawarani: Formal analysis and investigation. Widiyastuti: Supervision, Formal analysis and investigation. Heru Setyawan: Conceptualization, Methodology, Writing original draft preparation, and Supervision, Formal analysis and investigation, Writing - review and editing, Funding acquisition.

\section{References}

1. Li X, Xiong Y, Chen D, Zou C. Utilization of nanoparticle-stabilized foam for gas well deliquification. Colloids and Surfaces A: Physicochemical and Engineering Aspects 2015;482:378-385. https://www.sciencedirect.com/science/article/ pii/S0927775715004483.

2. Riza MF, Hasan AR, Kabir CS. A Pragmatic Approach To Understanding Liquid Loading in Gas Wells. SPE Production \& Operations 2016 08;31(03):185-196. https://doi.org/10.2118/170583-PA

3. Fameau AL, Salonen A. Effect of particles and aggregated structures on the foam stability and aging. Comptes Rendus Physique 2014;15(8):748-760. https://www.sciencedirect.com/science/article/pii/S1631070514001364 liquid and solid foams / Mousses liquides et solides. 
4. WU J, LEI Q, XIONG C, CAO G, ZHANG J, LI J, et al. A nano-particle foam unloading agent applied in unloading liquid of deep gas well. Petroleum Exploration and Development 2016;43(4):695-700. https://www.sciencedirect.com/science/ article/pii/S1876380416300817

5. Yang J, Jovancicevic V, Ramachandran S. Foam for gas well deliquification. Colloids and Surfaces A: Physicochemical and Engineering Aspects 2007;309(1):177-181. https://www.sciencedirect.com/science/article/pii/S0927775706007503 a Collection of Papers Presented at the 6th Eufoam Conference, Potsdam, Germany, 2-6 July, 2006.

6. Simjoo M, Rezaei T, Andrianov A, Zitha PLJ. Foam stability in the presence of oil: Effect of surfactant concentration and oil type. Colloids and Surfaces A: Physicochemical and Engineering Aspects 2013;438:148-158. https://www.sciencedirect. com/science/article/pii/S0927775713004524, a collection of papers presented at the 9th EUFOAM Conference, Lisbon, Portugal, 8-11 July 2012.

7. Bru DV, Ángel Rodríguez Martínez. Macroporous Silicon: Technology and Applications. In: Talanin VI, editor. New Research on Silicon Rijeka: IntechOpen; 2017.https://doi.org/10.5772/67698

8. Lee SY, Widiyastuti W, Iskandar F, Okuyama K, Gradoń L. Morphology and Particle Size Distribution Controls of Dropletto-Macroporous/Hollow Particles Formation in Spray Drying Process of Colloidal Mixtures Precursor. Aerosol Science and Technology 2009;43(12):1184-1191. https://doi.org/10.1080/02786820903277553.

9. Witoon T, Chareonpanich M. Effect of pore size and surface chemistry of porous silica on CO2 adsorption. Songklanakarin Journal of Science and Technology 2012;34(4):403-407.

10. Cho K, Chang H, Kil DS, Park J, Jang HD, Sohn HY. Mechanisms of the Formation of Silica Particles from Precursors with Different Volatilities by Flame Spray Pyrolysis. Aerosol Science and Technology 2009;43(9):911-920. https://doi. org/10.1080/02786820903025986

11. Santamaría E, Maestro A, Porras M, Gutiérrez JM, González C. Preparation of structured meso-macroporous silica materials: Influence of composition variables on material characteristics. Journal of Porous Materials 2014;21(3):263-274.

12. Yoon IH, Jung CH, Yoon SB, Park SY, Moon JK, Choi WK. Effect of silica nanoparticles on the stability of decontamination foam and their application for oxide dissolution of corroded specimens. Annals of Nuclear Energy 2014;73:168-174. https://www.sciencedirect.com/science/article/pii/S0306454914003090

13. Ajiz H, Mawarani L, Widiyastuti W, Setyawan H. Peningkatan Stabilitas Busa dengan Nanofluida Silika Untuk Meningkatkan Produksi Gas Alam. BERKALA SAINSTEK 2020;8(1):6-10. https://jurnal.unej.ac.id/index.php/BST/ article/view/15401

14. Mawarani LJ, Ajiz HA, Widiyastuti W, Setyawan H. Effect of nanosilica on foam stabilities of sodium lauryl sulfate and polysorbate mixture. AIP Conference Proceedings 2020;2219(1):030002. https://aip.scitation.org/doi/abs/10.1063/5. 0003006

15. Chaudhary S, Rohilla D, Mehta SK. Surfactant adsorption and aggregate structure of silica nanoparticles: A versatile stratagem for the regulation of particle size and surface modification. Materials Research Express 2014;1(1):015011.

16. Yusuf S, Manan M, Jaafar MZ. Aqueous Foams Stabilized by Hydrophilic Silica Nanoparticles via In-Situ Physisorption of Nonionic TX100 Surfactant. Iranica Journal of Energy \& Environment 2013;4(1):8-16.

17. Qomariyah L, Sasmita FN, Novaldi HR, Widiyastuti W, Winardi S. Preparation of Stable Colloidal Silica with Controlled Size Nano Spheres from Sodium Silicate Solution. Materials Science and Engineering 2018;395(1):012017.

18. Wang L, Yoon RH. Hydrophobic Forces in the Foam Films Stabilized by Sodium Dodecyl Sulfate: Effect of Electrolyte. Langmuir 2004;20(26):11457-11464. https://doi.org/10.1021/la048672g. pMID: 15595770.

19. Vatanparast H, Shahabi F, Bahramian A, Javadi A, Miller R. The Role of Electrostatic Repulsion on Increasing Surface Activity of Anionic Surfactants in the Presence of Hydrophilic Silica Nanoparticles. Scientific Reports 2018 8:1 2018 may;8(1):1-11. https://www.nature.com/articles/s41598-018-25493-7 
20. Hunter TN, Wanless EJ, Jameson GJ, Pugh RJ. Non-ionic surfactant interactions with hydrophobic nanoparticles: Impact on foam stability. Colloids and Surfaces A: Physicochemical and Engineering Aspects 2009;347(1):81-89. https://www. sciencedirect.com/science/article/pii/S0927775708008923, interfaces Against Pollution.

How to cite this article: Ajiz H.A., Mawarani L.J., Widiyastuti W., Setyan H. (2021), High-Stability Foam of Silica Nanofluid to Overcome Liquid Loading in Enhancing Natural Gas Production, IPTEK The Journal of Technology and Science, 32(1):23-30. 